\title{
LOW ORGAN DONATION RATE IN MALAYSIA: A SURVEY
}

\author{
Makmor $T^{1}$, Abdillah $N^{2}$, Raja Noriza RA ${ }^{1}$, Nurulhuda MS ${ }^{3}$, Sook-Lu $Y^{3}$, Soo-Kun L4, Kok-Peng $N^{4}$ \\ 1 Department of Administrative Studies and Politics, Faculty of Economics and Administration, University of Malaya, \\ Kuala Lumpur \\ 2 Tun Abdul Razak School of Government, Universiti Tun Abdul Razak, Kuala Lumpur \\ 3 Department of Economics, Faculty of Economics and Administration, University of Malaya, Kuala Lumpur \\ 4 Department of Medicine, Faculty of Medicine Building, University of Malaya, Kuala Lumpur
}

\section{Correspondence:}

Makmor Tumin

Department of Administrative Studies and Politics, Faculty of Economics and Administration, University of Malaya, 50603

Kuala Lumpur.

E-mail:makmor@um.edu.my

\begin{abstract}
Organ shortage is a major concern in many countries. The objective of this paper was to investigate the factors that contribute to the low quantity of organ donation in Malaysia. The 1311 respondents in this survey came from the three main ethnic groups in Malaysia (Malay, Chinese and Indian). The survey was based on these components: The reason for not pledging to become a donor; the reason of refusing to become a donor; and whether non-fungible incentive would influence decision. The lack of information and trust were the factors that influenced the respondents to remain apathetic to organ donation. The results denote that people are unlikely to become a donor even if non-fungible incentive were provided to them. Thus, it is important for the government bodies to evaluate the programme and strategies of public education in relation to organ donation.
\end{abstract}

Keywords: Malaysia, organ donation, organ donation rate, organ shortage, public education

\section{Introduction}

World over, the demand for organs far outweigh supply and Malaysia has one of the lowest deceased organ donation rates $(0.48$ donations per million populations in 2010) in the world. A similar scenario can be seen in countries like Myanmar (0.02), Guatemala (0.52), Bulgaria (1.14) and Thailand (1.26) (1).

One of the suggestions to overcome the problem of organ shortfall is for countries to implement the opt-out consent policy $(2,3,4)$. Countries that follow the opt-out consent policy such as Spain (34.13), Belgium (25.61), France (25.31) and Austria (20.72) (1) have all experienced better rates of organ donation. While it is important to consider the opt-out consent policy, there are other policies that attempt to encourage organ donation. The range include: introducing paired organ donation drive where families of both the deceased donor and living donor are rewarded; promoting altruistic approaches by advocating the values of good Samaritan advocacy; implementing appropriate educational programs for the public and hospital staff regarding the need and benefits of organ donation; and managing the financial payment for the donor (5).

Some studies in Malaysia suggest the possibility of religiocultural factor as the main impediment to organ donation in Malaysia $(6,7)$, while others suggest low organ donation - especially among the post-secondary education group as the result of the public lack of trust toward the medical system (8). In another study, there was a proposal that non-fungible incentives would positively influence the way people react to organ donation (9). To facilitate organ donation, Malaysia introduced the Human Tissue Act in 1974, followed by a National Transplantation Program in 1975. The first living kidney transplant was performed in Malaysia in 1975 and the first deceased donation follow suit two years later.

Much later in 2007, Malaysia strengthened its existing transplantation policy by introducing the National Organ, Tissue and Cell Transplantation Policy. More recently, in 2011, the Government came out with a guideline and procedures to embark on 'unrelated living donation.' The effort though has given little effect. Up to December 2011, there were only 1122 kidney transplantation involving living donors, while only 378 transplantation involving deceased donors were recorded as of 31 July 2012 (10).

This paper is an attempt to explain the reasons that impede Malaysians to become donors by broadening our analysis to cover Malaysia's population on their willingness to become donor. 


\section{Methods}

A survey to gauge public opinion on becoming deceased donor was carried out in the Klang Valley (Kuala Lumpur and its suburbs) between October and December 2010. Klang Valley was chosen because of its mixed ethnic population that mirrors Malaysia's demographic profile. The survey's ethnic breakdown also mirrors Malaysia's and Klang Valley's demographic profile: 58.1\% Malays, 26.8\% Chinese, $11.5 \%$ Indians and $3.6 \%$ others.

In the survey, 1420 people were approached, out of which 1311 agreed to do the survey, giving a response rate of around $91.5 \%$. The enumerators were asked to approach people at three designated spots - university campuses, hospitals and eateries. The three locations were chosen due to the need of selecting area where diverse demographic characteristics of respondents can be found. University campuses for example, are the most possible location to gauge young peoples' views on organ donation. Hospitals are captive ground for potential organ donors and those with strong views on health issues, while eateries provide a ground for a wider spectrum of respondents. The enumerators were also asked to adhere to Malaysia's ethnic composition when approaching potential respondents. They were instructed to cease approaching people of an ethnic group when the quota for that particular group has been fulfilled.

After filling-up their background information in the questionnaire, the respondents were presented with a specific question, "Are you willing to donate your organ upon death?" This question is important to separate respondents into two clear-cut categories for further investigation: those who are willing and those who are unwilling to donate. In the following part of the questionnaire, we asked those willing donors on their reason for not registering as deceased donor despite saying "yes" to donation. Five options were given to them and they were allowed to choose more than one options. The options were: (i) I do not know the procedures on how to register; (ii) Still waiting for my family's consent; (iii) No motivation whatsoever to do so; (iv) Due to time constraint and, (v) Others.

The last two parts of the questionnaire were directed to the group who were unwilling to become deceased donor. We began to investigate the non-willing donors group by examining the reasons for the unwillingness. They were given two set of options. The first set of options was based on religio-cultural considerations: "It is against my religion" and "I want my body to remain intact after death." The second set was based on structural considerations: "I am not convinced that my organ/body part will be used beneficially" and "I do not have access to the information."

Next, we investigated the group who were unwilling donors on the possibility of them changing their mind. There were given two options: one, which is based on the importance of public education and the other, a policy driven by monetary incentive. The first question asked was, "Are you going to register as a deceased organ donor if you and your family were provided with sufficient information on the entire process of donation: from registration to the point of donation?" The second question was, "Are you going to register as a deceased organ donor if special benefits such as tax rebates were provided to registered donors?" This information will help in establishing people's preferences: whether they are more responsive to proper awareness campaigns or instead, more responsive to non-fungible incentive-driven policy.

\section{Results}

The breakdown of the respondents by ethnic group from the survey are as follows: 762 Malays (58.1\%), 351 Chinese (26.8\%), 151 Indians (11.5\%) and 47 'Others' (3.6\%). Respondents' religious affiliations reflect Malaysia's religious diversity: 779 (59.4\%) of respondents were Muslims, 269 (20.5\%) Buddhists, 126 (9.6\%) Hindus, 115 (8.8\%) Christians and 22 (1.7\%) were other religions. Majority of the respondents have tertiary (688 persons, $52.5 \%$ ) and secondary (584 persons, $44.5 \%$ ) education and $37.5 \%$ respondents (491 persons) earn RM1000 and below. Female respondents outnumbered male respondents: there were 720 females (54.9\%) compared to 591 males. Six hundred and forty five respondents (49.2\%) were in the category of ' 25 years and below' age group, with 373 (28.5\%) in the '26-35 years'age bracket and the remaining $293(22.3 \%)$ in the '36 years and above' age category.

The results showed 581 (44.3\%) answered "yes" and 730 (55.7\%) answered "no" to the question "Are you willing to donate your organ upon death?" Out of the 581 who said "yes", only 25 (4.3\%) are registered organ donors. The following are the reasons of the 556 respondents (581-25) who still do not register as organ donors despite saying "yes" to donation (Table 1). The results clearly indicated that the reason "I do not know the procedure on how to register" recorded the highest score (285), followed by "No motivation whatsoever" (149). These observations suggested the importance of a concerted effort to inform the public not only on the importance of organ donation but also on the procedure of becoming a registered donor.

The results from the group who said "no" to be a donor (730) are presented in Table 2 and 3. Table 2 shows the reason why they said "no."

Under the structural considerations, two factors registered the highest score: the lack of accessibility to information and the lack of trust on the beneficial utilisation of their organ upon donation. Both scenarios reemphasize the above findings on the importance of channelling sufficient information to attract potential donors. The results clearly indicate that structural considerations (the lack of accessibility to information and the lack of trust on the beneficial utilisation of their organ upon donation) as opposed to religio-cultural considerations (against their religion and want their body to remain intact after death) scored the highest -254 and 254 respectively. 
Table 1. Reasons not to be a registered organ donor by ethnic group

\begin{tabular}{lccccc}
\hline \multirow{2}{*}{ Factor } & \multicolumn{3}{c}{ Score } \\
\cline { 2 - 6 } & Malay & Chinese & Indian & Others & Total \\
\hline I do not know the procedures on how to register & 157 & 72 & 46 & 10 & 285 \\
Still waiting for my family's consent & 46 & 51 & 16 & 2 & 115 \\
Due to time constraint & 53 & 32 & 18 & 2 & 105 \\
No motivation whatsoever & 101 & 31 & 11 & 6 & 149 \\
Others & 60 & 45 & 12 & 134 \\
\hline
\end{tabular}

Note: The respondents were allowed to choose more than one options, therefore the score presented is the total number of response for each factor.

Table 2. Factors influencing respondents' decision not to be an organ donor by religious affiliations

\begin{tabular}{|c|c|c|c|c|c|c|}
\hline & Muslim & Christian & Buddhist & Hindu & Others & Total \\
\hline \multicolumn{7}{|l|}{ Religio-cultural } \\
\hline It is against my religion & 68 & 5 & 24 & 5 & - & 102 \\
\hline I want my body to remain intact after death & 113 & 9 & 24 & 5 & 2 & 153 \\
\hline \multicolumn{7}{|l|}{ Structural } \\
\hline I do not have access to the information & 187 & 13 & 40 & 11 & 3 & 254 \\
\hline $\begin{array}{l}\text { I am not convinced that my organ/body part } \\
\text { will be used beneficially }\end{array}$ & 186 & 14 & 35 & 18 & 1 & 254 \\
\hline Others & 122 & 15 & 42 & 11 & 6 & 196 \\
\hline
\end{tabular}

Table 3. Non-willing donors' attitude toward incentive and information by level of education

\begin{tabular}{lllcc}
\hline Level of education & Factor & Yes & No & Undecided \\
\hline Pre-tertiary & Tax rebate & 52 & 201 & 93 \\
& Adequate information is provided to respondents and their family. & 74 & 211 & 99 \\
Post-secondary & Tax rebate & 70 & 159 & 117 \\
& Adequate information is provided to respondents and their family. & 90 & 170 & 124 \\
& Total & 286 & 741 & 433 \\
\hline
\end{tabular}

Contrary to popular belief, religio-cultural is not the main impediment for people to become a donor compared to responds associated to structural considerations.

The results shown in Table 3 indicated that if the respondents, who were initially unwilling to donate their organs, were provided with adequate and complete information about the donation procedure, they will be more likely to be willing to donate, regardless of the level of education. In fact, the result shows that people are less likely to react to policies driven by monetary incentive, such as tax rebate compared to the desire for information.

When both level of education are combined, the results indicate that only 122 respondents were willing to change their mind to become a donor if tax rebate were offered but a greater number (164) would be willing to change their mind if complete information were given. It can be deduced from the results that monetary incentive may not be a sufficient inducement to one's decision to donate.

\section{Discussion and Conclusion}

The results bear some interesting conclusions. First, there is indeed a huge population of potential donor in Malaysia. Second, many citizens do not register for organ donation because they do not know the registration procedure. Third, the lacking of information and trust were the main reasons why they do not want to donate and, finally, people in Malaysia are more likely to change their view from not donating to donating their organs if adequate information were provided to them, rather than incentive.

The above findings may suggest that the lack of effective public education on organ donation may be the main cause of low organ donation rate and organ shortage in Malaysia; and elevating the investment in public education on organ donation may probably address the said problem.

Currently, conventional methods and strategies are commonly employed to educate the Malaysian public on organ donation. For instance, using living donors as role 
models in campaigns, organising talk shows or organising sports event to create organ awareness. Meritorious as these efforts may be, these events have not turned in the result. As such, public education efforts hosted by the authorities and relevant stakeholders should not be limited only to organizing events that are macro in nature, but also activities that touches individuals at the personal level. One among the effective ways is to target the family, as studies have indicated that targeting individual families can better increase the chance of individuals to pledge for organ donation $(11,12,13)$. The authorities may also target families of chronic patients, such as family members of dialysis patients. Employing such a niche approach could well influence one's decision to donate as family members of a chronic patients may be able to better relate to problems of organ failure. In fact, our preliminary research on this group has confirmed such claim; that is, the survey found that $80 \%$ respondents (family members of dialysis patients) were willing to be deceased donor while $35 \%$ of respondents had signed the organ donation pledge at the time the survey was conducted (14). Besides families of chronic patients, education on organ donation could also be meted out to care providers of chronic patients; medical staff and social workers who were closely associated with the patient.

Apart from the above, organising campaigns that appeal to the cultural, social and religious preferences of target communities could also increase organ donation pledges.

Effective public education could well complement possible policy decision to implement the "opt-out" rather than "opt-in" strategy that has proven to be successful in many advanced countries. Public education could also address issues relating to cultural-religio factors to allay fears on organ donation. Also more importantly, public education could well address Malaysia's palpable number of deceased organ donations which could prove to be the best option at addressing organ shortage.

The potential for organ donation in Malaysian population is largely unexplored. The current study indicates that insufficient information on organ donation and lack of trust towards the medical system are the main causes to low organ donation rate in the country. Re-evaluation and improvement of the current national programme and policies on organ donation to facilitate effective public education are thus crucial to enhance public awareness and acceptance towards organ donation, so as to address the problem of organ shortage in Malaysia.

\section{Acknowledgement}

The authors wish to thank the University of Malaya for funding the research under the University of Malaya Research Grant Schemes 2010 and 2012 (Project No.: UMRG 195/10HTM and ERGS 019-2012A).

\section{References}

1. Global Observatory on Donation and Transplantation. Final report on organ donation and transplantation: activities, laws and organization in 2010. http://www. transplant-observatory.org/Pages/DataReports. aspx. Accessed May 4, 2012.

2. Rithalia A, McDaid C, Suekarran S, et al. Impact of presumed consent for organ donation rates: a systematic review. BMJ 2009; 338: a3162.

3. Eaton S. The subtle politics of organ donation: a proposal. J Med Ethics 1998; 24:166-170.

4. Bird SM, Harris J. Time to move to presumed consent for organ donation. BMJ 2010; 340:c2188.

5. Abouna GM. Organ shortage crisis: problems and possible solutions. Transplant Proc 2008; 40:34-38.

6. Muda FS. A socio-legal study on organ shortage in Malaysia. [dissertation]. The University of Southampton, 2012.

7. Loch A, Hilmi IN, Mazam Z, Pillay Y, Choon DSK. Differences in attitude towards cadaveric organ donation: Observations in a multiracial Malaysian society. Hong Kong J Emerg Me. 2010; 17(3):236-243.

8. Tumin M, Noh A, Jaji I, Chong CS, Manikam R, Abdullah N. Factors that hinder organ donation: Religio-cultural or lack of information and trust. Exp Clin Transplant 2013; 11(3):207-210.

9. Tumin $\mathrm{M}$, et al. Non-organ donors' attitudes toward incentives. Clin Transplant 2013; 27(3):E316-E319.

10. National Renal Registry, Ministry of Health Malaysia. 19th Report of the Malaysian Dialysis and Transplant Registry 2011. http://www.msn.org. my/fwbPagePublic.jsp?fwbPageld=pMdtr2011.4. Accessed 17 Jul 2012.

11. Dejong W, Drachman J, Gortmaker SL, et al. Options for increasing organ donation: the potential role of financial incentives, standardize hospital procedures and public education to promote family discussion. Milbank Q 1995; 73:463-479.

12. DeJong, $W$, et al. Requesting organ donation: an interview study of donor and non-donor families. Am J Crit Care. 1998; 7(1):13-23.

13. Morgan, Susan E., and Jenny K. Miller. Beyond the organ donor card: The effect of knowledge, attitudes, and values on willingness to communicate about organ donation to family members. Health Commun. 2002; 14(1):121-134.

14. Author's preliminary survey, "Organ donation awareness campaigns targeted at families of dialysis patients," July 2012. 